\title{
As desigualdades sociais no acesso a cuidados de saúde em reprodução contínua
}

\author{
Social inequalities in access to health care in \\ continuous reproduction
}

\author{
Las desigualdades sociales en el acceso a la \\ atención sanitaria en reproducción continua
}

Claudia Travassos 1

doi: 10.1590/0102-311X00108818

Agradeço o convite para participar do debate acerca do artigo da Professora Ligia Bahia sobre os 30 anos do SUS. Debater o SUS é uma necessidade permanente que deve ser estimulada nos mais diversos fóruns, também como prerrogativa de sua permeabilidade às permanentes mudanças na sociedade e suas demandas. Este debate ganha especial relevância na conjuntura em que vivemos de desmonte de direitos e políticas sociais vinculado aos constantes ataques à Constituição Federal de 1988.

Acredito que a longa experiência de pesquisa e de militância da autora na questão do setor privado na saúde nos oferece um olhar particular sobre a trajetória do SUS, com elementos que têm sido pouco revelados, apesar de centrais para a compreensão dos atuais desafios. Já na abertura, a autora denuncia que o SUS, após 30 anos de existência, cresceu sem ter se tornado único nem universal, mesmo sendo estes princípios estruturantes da legislação que lhe dá suporte, que lhe define democrático. A trajetória do SUS evidencia um processo de implementação cronicamente incompleto do projeto democrático na Saúde, independentemente dos inegáveis avanços tanto na saúde das pessoas como no acesso a cuidados de saúde. Permanece incompleta especificamente porque a conquista plena de direitos constitucionais se vê impedida pela contínua reprodução e mesmo produção, em algumas circunstâncias específicas, daquela que é a marca mais abjeta da sociedade brasileira, suas profundas desigualdades sociais. No entanto, na visão da autora, esse não seria o único resultado possível e o SUS poderia ter gerado desfechos mais igualitários.

Meu principal comentário sobre o artigo vai centrar exatamente na reflexão acerca da questão anterior. Argumentos que empreguei, em minha Tese de Doutorado 1, sobre equidade nos hospitais privados contratados pelo Instituto Nacional de Assistência Médica da Previdência Social (Inamps, em 1986), denotavam que as características plurais do sistema de saúde brasileiro, nos períodos que precederam à Constituição de 1988, não se dissociavam das enormes desigualdades sociais existentes na sociedade. A oferta pública e privada de cuidados de saúde era moldada por grandes variações entre e intra cada um desses setores na distribuição territorial dos serviços, tipo de cuidado prestado, fontes de financiamento, modo de pagamento aos prestadores, tipo, quantidade e qualidade do cuidado, e podemos ainda acrescentar a este elenco o preço e o custo dos procedimentos diagnósticos e terapêuticos. Resultava daí um sistema de saúde fragmentado, refinadamente iníquo e já à época razoavelmente intrincado.
1 Instituto de Comunicação e Informação Científica e Tecnológica em Saúde Fundação Oswaldo Cruz, Rio de Janeiro, Brasil.

\section{Correspondência} Departamento de Informações para a Saúde, Instituto de Comunicação e Informação Científica e Tecnológica em Saúde, Fundação Oswaldo Cruz. Av. Brasil 4365, Rio de Janeiro, RJ 21045-900, Brasil.

claudia.maria.travassos@ gmail.com 
O intervalo entre o panorama que descrevi naquele momento e o apresentado neste debate corresponde a um pouco mais do que os 30 anos de existência do SUS. Ao longo do tempo, o que se observa é um setor privado capaz de se modificar, de permanentemente recriar novos arranjos, mas que se correlacionam, inevitavelmente, a um padrão maior ou menor de iniquidade no acesso a cuidados de saúde. A autora demonstra de várias maneiras como o setor privado no período recente se mostrou uma vez mais capaz de manter presença predominante no sistema de saúde brasileiro, reconfigurado e alimentando as enormes distorções na distribuição social de acesso a cuidado de saúde de qualidade. Seus representantes manejam com sucesso seus interesses, influenciando, mesmo que em intensidades distintas, governos de composição política diversa, em conjunturas extremamente variáveis e na contramão dos princípios constitucionais. É interessante, como destacado no artigo, identificar como setores externos ao Ministério da Saúde, além do Legislativo, atuaram em anos recentes explicitamente em franca oposição aos princípios constitucionais.

Ligia nos apresenta algumas configurações das atuais e intricadas relações horizontais (entre) e verticais (intra) os setores público e privado e suas consequentes iniquidades. Destaco a variação dos preços médios das internações entre o setor público e o setor privado, com grande vantagem para as internações pagas por recursos privados, que apresentam valores médios cerca de cinco vezes maiores do que aqueles pagos por recursos públicos. Essas variações também se repetem em escala menor, ainda que com magnitudes inaceitáveis, entre hospitais privados, filantrópicos ou não. Variações no perfil clínico desses pacientes não são capazes de explicar tamanha diferença e, portanto, refletem pacotes de cuidado diferenciados prestados a pacientes com condições clínicas semelhantes. Via de regra, essas variações estão associadas à diferença na composição social da demanda, agravando as desigualdades sociais no cuidado de saúde. A chegada das Organizações Sociais no setor saúde vem desmanchar ainda mais os limites já bastante intrincados entre público e privado. Portanto, o redesenho progressivo desses limites pode ser entendido como resultado da efetiva e persistente estratégia de ampliação de espaço do setor privado sobre o público, reconhecida pela autora do debate. $\mathrm{Na}$ verdade, o que é expresso como questão de "indefinição de fronteira" que impede a universalização, parece ser menos indefinição e mais intenção da recente estratégia do setor privado.

Para descrever os estabelecimentos de saúde a autora optou pelo emprego das categorias público, filantrópico e privado, que expressam aparentemente apenas a sua natureza jurídica. Ao deixar de considerar outros aspectos relevantes para uma configuração mais confiável dos estabelecimentos de saúde, como as fontes de pagamento do cuidado prestado aos distintos pacientes e a natureza da gestão, se pública ou privada, relações de propriedade, entre outras, dificultaram a compreensão do leitor e limitaram o aprofundamento da análise desses múltiplos mercados e suas nuances que se expressam em agendas políticas e projetos setoriais particulares ou mesmo competitivos entre si. A complexidade desse panorama aumenta quando incluídos os planos privados de saúde, subsetor extremamente dinâmico e financeirizado, objeto particular de estudo da autora do Debate. Carências e dificuldades para produzir informação que permita maior detalhamento no mapeamento da estrutura e desempenho das múltiplas configurações em atuação hoje no setor saúde não devem inibir que classificações mais complexas sejam propostas e mesmo testadas, por serem críticas para a compreensão da dinâmica do setor, esforço que em vários aspectos vem sendo realizado pelo Grupo de Pesquisa sobre Documentação e Empresariamento na Saúde, Instituto de Estudo em Saúde Coletiva, Universidade Federal do Rio de Janeiro, entre outros que buscam aprofundar a questão da privatização no setor saúde.

Por fim, penso que a evidente intolerância de alguns grupos sociais em aderir a políticas igualitárias associadas à ampla valorização e preferência ao setor privado, em detrimento do público, espelha o ainda precário debate na sociedade brasileira sobre o significado do direito à saúde e a vulnerabilidade a que ficam submetidos amplos setores da população na vigência de um sistema de saúde com dominância do setor privado. As ideologias que estruturam a agenda privada na saúde precisam ser estudadas, e ampla, sistemática e cotidianamente debatidas e criticadas para construirmos o caminho em direção ao SUS único e universal. 
1. Travassos Veras CM. Equity in the use of private hospitals contracted by a compulsory insurance scheme in the city of Rio de Janeiro, Brazil, in 1986 [Tese de Doutorado]. London: London School of Economics and Political Science; 1992.

Recebido em 03/Jun/2018

Aprovado em 06/Jun/2018 